AperTO - Archivio Istituzionale Open Access dell'Università di Torino

\title{
May an adrenal incidentaloma change its nature?
}

\section{This is the author's manuscript}

Original Citation:

Availability:

This version is available http://hdl.handle.net/2318/1742717

since 2021-02-01T11:36:00Z

Published version:

DOI:10.1007/s40618-020-01219-3

Terms of use:

Open Access

Anyone can freely access the full text of works made available as "Open Access". Works made available under a Creative Commons license can be used according to the terms and conditions of said license. Use of all other works requires consent of the right holder (author or publisher) if not exempted from copyright protection by the applicable law. 


\section{May an adrenal incidentaloma change its nature?}

1 Alessandra Müller ${ }^{1}$, Elisa Ingargiola ${ }^{1}$, Federica Solitro ${ }^{2}$, Enrico Bollito ${ }^{3}$, Soraya Puglisi ${ }^{*}$, 2 Massimo Terzolo ${ }^{1}$, Anna Pia ${ }^{1^{* *}}$, Giuseppe Reimondo ${ }^{1^{* *}}$.

$3 \quad * *$ have equally contributed as senior authors

$4{ }^{1}$ Internal Medicine, Department of Clinical and Biological Sciences, San Luigi Gonzaga Hospital, University of Turin, 5 Orbassano, Italy

$6 \quad{ }^{2}$ Radiology, Department of Oncology, San Luigi Gonzaga Hospital, University of Turin, Orbassano, Italy

$7 \quad{ }^{3}$ Pathology, Department of Oncology, San Luigi Gonzaga Hospital, University of Turin, Orbassano, Italy

9 * Corresponding Author: Soraya Puglisi

10 Internal Medicine, Department of Clinical and Biological Sciences, San Luigi Gonzaga Hospital,

11 Regione Gonzole 10, 10043 Orbassano, Italy; tel: +39 011 9026292, fax: +39 0116705456

12 e-mail: sorayapuglisi@yahoo.it ORCID: 0000-0002-2883-6139

14 Keywords: incidentaloma, adrenal tumor, metastasis, PET, uptake, adrenalectomy, follow-up, lung 15 cancer.

17 Author Contributions: Clinical management of the patient: AP; Imaging review: FS; Pathological

18 review: EB; Drafting of the Manuscript: AM, EI; Critical Review of the Manuscript: SP, AP, GR,

19 MT; Supervision: AP, GR, MT. 


\section{Abstract}

21 Up to $70 \%$ of adrenal masses detected in patients affected by extra-adrenal malignancy are metastatic

22 lesions. Therefore, detection of an adrenal mass in patients with active or previous malignancy

23 requires a careful differential diagnostic work-up. ${ }^{18}$ F-Fluorodeoxyglucose-positron emission

24 tomography/computed tomography $\left({ }^{18} \mathrm{~F}-\mathrm{FDG}-\mathrm{PET} / \mathrm{CT}\right)$ is increasingly used to determine the

25 malignant potential of adrenal lesions.

26 We report the case of a 64-year-old man who had a single adrenal metastasis due to non-small-cell

27 lung carcinoma developing on a pre-existing benign adrenal lesion. This metastasis occurred in a

28 phase of perceived oncological remission and was detected thanks to ${ }^{18} \mathrm{~F}-\mathrm{FDG}$-PET/CT showing a

29 focal adrenal uptake. Contrast-enhanced computed tomography (CT), performed as part of

30 oncological follow-up, and MRI with chemical shift sequences did not lead to the correct diagnosis.

31 The patient underwent laparoscopic adrenalectomy and the pathological evaluation confirmed a lung

32 carcinoma metastasis.

33 The present case highlights the peculiarity of the follow-up of adrenal masses in cancer patients and

34 the primary role of ${ }^{18} \mathrm{~F}-\mathrm{FDG}-\mathrm{PET} / \mathrm{CT}$ in the management of such patients. 
37 About $2 \%$ of all incidentally detected adrenal masses are of metastatic nature. This percentage rises

38 to $30-70 \%$ in patients affected by an extra-adrenal malignancy [1] . The adrenal gland represents

39 indeed a frequent site of metastasis, due to its rich sinusoidal vascularization. Lung cancer followed

40 by breast cancer and melanoma are most likely to spread to the adrenal gland [2] . Rare cases of

41 collision tumors, defined as the coexistence of two different tumors in an adrenal gland, such as an

42 adrenal adenoma and an adrenal cancer or a metastatic tumor, have been described [3].

43 Although no randomized study comparing imaging tests has been performed, non-contrast computed

44 tomography (CT) is generally considered as the first-line imaging test to make a differential

45 diagnosis between benign and malignant adrenal masses. Whenever the mass is considered of

46 indeterminate nature after non-contrast CT, second-line imaging tests, including CT with delayed

47 contrast media washout, chemical shift MRI, and ${ }^{18} \mathrm{~F}$-FDG-PET/CT, are needed to define the

48 diagnosis [4]. Once that an adrenal incidentaloma is considered to be a benign lesion after an

49 appropriate work-up, it is not recommended to pursue a specific follow-up with repeated imaging

50 studies [4]. The recommendation is based on the very low chance that a benign adrenal lesion may

51 turn in a malignant one during follow-up [5].

52 We report here in a case that represents an exception to this general rule and underlines the 53 challenges that may arise in the diagnosis of adrenal metastases.

\section{Case presentation}

56 The patient is a 64-year-old man, ex-smoker (10 cigarettes/day), with an occupational exposure to

57 silica dust and asbestos and a clinical history of chronic obstructive pulmonary disease and arterial 58 hypertension. In 2008, a left adrenal nodule was occasionally detected and investigated with 
endocrinological workup and non-contrast CT, which were suggestive for a benign, non-functioning,

60 adrenal adenoma. The lesion was of $30 \mathrm{~mm}$ in size with a density $<0$ Hounsfield Units (HU) [Figure

$611]$.

62 In August 2015, a squamous cell carcinoma of the upper lobe of the right lung with mediastinal

63 lymphadenopathy was diagnosed. The patient was treated with chemo- and radiotherapy with

64 complete disease response and subsequent negative radiological follow-up.

65 In September 2017, a follow-up total body contrast-enhanced CT scan showed multiple pulmonary

66 lesions and a slight enlargement of the known left adrenal nodule (37 mm diameter) [Figures 2a and

67 2b]. Hounsfield Units and morphological characteristics were not reported. Due to the suspect of

68 disease recurrence a ${ }^{18}$ F-FDG-PET/CT scan was performed and it showed a focal pathological uptake

69 in the left adrenal region without relevant uptakes in other sites (absolute SUV value 7.8,

70 adrenal/liver ratio 3.5) [Figure 2c], while the pulmonary lesions resolved after antibiotic therapy.

71 The patient was then referred to our outpatient unit. A hormonal workup was negative for

72 hypercortisolism, primary hyperaldosteronism and catecholamine excess. All the available CT scans

73 were re-evaluated by an expert radiologist, who confirmed the increase in size $(7 \mathrm{~mm})$ and described

74 the adrenal mass as inhomogeneous with faintly irregular borders. Due to the changed radiological

75 characteristics an adrenal magnetic resonance imaging (MRI) with chemical shift sequences was

76 performed but was not conclusive in the differential diagnosis between a lipid-poor adenoma and a

77 malignant lesion, showing incomplete, inhomogeneous signal intensity loss in out-of-phase

78 sequences [Figures $3 \mathrm{a}$ and $3 \mathrm{~b}]$.

79 Following the pathological adrenal uptake at FDG-PET scan, not justified by an autonomous

80 hormone production, and the undetermined radiological characteristics at MRI the patient underwent

81 left laparoscopic adrenalectomy with an uneventful course. The pathological exam revealed that the

82 adrenal parenchyma was completely replaced by squamous carcinoma cells, with typical

83 adenomatous cells surrounding the central neoplastic core [Figures $4 \mathrm{a}$ and $4 \mathrm{~b}$ ]. 


\section{Discussion}

86 Whether most adrenal masses detected in patients affected by extra-adrenal malignancies are of

87 secondary nature, adrenal metastases are rarely found in non-oncological patients [1]. Therefore, a

88 history of known extra-adrenal malignancy requires a particular attention to the possibility of an

89 adrenal metastasis. A new adrenal lesion developing during oncological follow-up should also be

90 viewed as suspicious.

91 In clinical practice, the most commonly used imaging techniques to assess the risk of malignancy are:

92 non-contrast CT, MRI with chemical shift sequences, and ${ }^{18}$ F-FDG-PET/CT. The recent

93 ESE/ENSAT guidelines on the management of adrenal incidentalomas recommended non-contrast

$94 \mathrm{CT}$ as the first radiological test [4]. Adrenal lesions that are homogeneous, smaller than $4 \mathrm{~cm}$, with

95 density $<10$ Hounsfield units (HU) are considered benign, lipid-rich adenomas. However, about 30\%

96 of adrenal adenomas are lipid-poor and show an attenuation value $>10 \mathrm{HU}$ that overlaps with

97 malignant lesions and pheochromocytomas [6-8]. The use of MRI with chemical shift sequences is

98 based on the typical loss of signal intensity shown by intracellular lipid-rich lesions in out-of-phase

99 sequences, while lipid-poor adenomas, malignant lesions and pheochromocytomas remain unchanged

100 [9-11]. In patients with history of extra-adrenal malignancy, the ESE/ENSAT guidelines suggest the

101 use of ${ }^{18}$ F-FDG-PET/CT performed as part of oncological follow-up [4]. ${ }^{18}$ F-FDG-PET/CT has the

102 advantage of being able to detect malignant adrenal lesions with a low rate of false negatives (mainly

103 metastases from tumors with low FDG-uptake, i.e. kidney cancer [12]) and a certain rate of false

104 positives (i.e., functional adenomas [13]) [14]. Routine use of ${ }^{18} \mathrm{~F}-\mathrm{FDG}-\mathrm{PET} / \mathrm{CT}$ in patients without

105 history or suspect of malignancy is currently not recommended, but a recent prospective study

106 showed that it has an excellent negative predictive value in the characterization of indeterminate

107 and/or large adrenal masses in non-cancer patients [15]. 
108 In our patient, the contrast-enhanced CT performed during the oncological follow-up reported only a

109 slight enlargement of the known adrenal lesion and only the radiological revision, requested after the

$110{ }^{18}$ F-FDG-PET/CT, showed changes of the lesion's features. The ${ }^{18} \mathrm{~F}-\mathrm{FDG}-\mathrm{PET} / \mathrm{CT}$ was done

111 primarily for the suspect of pulmonary progression of disease but showed a single, focal uptake of

112 the known adrenal lesion. Since the mass has been previously recognized as benign, further

113 diagnostic tests were done. Hormone assessment was unrewarding, and MRI was still compatible

114 with a lipid-poor adenoma. Our case represents a "real-life" demonstration of the limits of

115 radiological and functional imaging in defining adrenal masses nature, especially in patients with

116 known oncological history. These limits have been widely analyzed in a systematic review and meta-

117 analysis [16] which laid the groundwork for the recommendations given by the ESE/ENSAT

118 guidelines, especially when second-line imaging techniques are used in indeterminate adrenal

119 masses. Despite the great potential of available radiological and functional imaging, there are not

120 only difficulties related to the heterogeneity of both benign and malignant adrenal lesions and to the

121 frequent overlap in imaging features [17], but also the expertise of the single radiologist and clinician

122 influence the patient's diagnostic pathway in clinical practice.

123 In our patient, since radiological and functional imaging were not conclusive in defining the nature of

124 the adrenal lesion's changes, a histopathological evaluation was considered essential. The

125 multidisciplinary team discussion considered the adrenal biopsy a possible choice, but since we had

126 a consistent suspicion of malignancy and the patient was in excellent clinical conditions with a

127 prolonged disease-free interval following oncological treatment of his non-small cell lung cancer

128 (NSCLC), we decided to be proactive and recommended surgical removal of the adrenal lesion. Our

129 choice was also supported by the expertise of our surgeon and the notion of a favorable outcome of

130 patients who underwent removal of solitary adrenal metastases from different cancer types, including

131 NSCLC. 
132 Since the first description of adrenalectomy for isolated metastasis in 1982 [18], many retrospective

133 series showed a potential benefit in survival in well-selected patients undergoing surgical treatment $134 \quad[19-26]$.

135 In recent years, there is growing evidence in support of use of laparoscopic approach in malignant

136 adrenal lesions ensuring an adequate oncologic result, in addition to the advantages of mini-invasive 137 surgery in terms of safety and post-operative recovery [27-30]. Therefore, laparoscopic

138 adrenalectomy represents the first-choice surgical option in these patients.

139 Given the low probability that a benign adrenal lesion becomes malignant during follow-up [5], an

140 active imaging surveillance of adrenal incidentalomas that are characterized to be benign is currently

141 not recommended $[4,31]$. However, oncological patients may represent a possible exception to the

142 rule because neoplastic cells may be seeded in a pre-existing benign lesion. Whether the coexistence

143 of a metastasis in an adrenal benign lesion is an incidental occurrence or represents the result of

144 changes in the local environment that may favor hematogenous metastatization in an adrenal

145 adenoma is not still clear. In 2014, Untch and colleagues [3] reviewed 11 histopathologically-proved

146 adrenal collision tumors described in literature. In the last five years other 14 case reports of adrenal

147 collision tumors have been published [3, 32-51]. The 25 cases are summarized in Table 1 . In 18

148 cases, an adrenal adenoma was present. In 17 cases a malignant component was described, in 6 cases

149 of primitive adrenal origin, in 11 cases of metastatic nature. 3 cases were lung cancer metastases, one 150 small cell lung carcinoma (SCLC) and two NSCLC.

\section{Conclusions}

153 In conclusion, we have reported the development of a solitary adrenal metastasis on a pre-existing 154 benign adrenal lesion in a patient with a NSCLC in apparent clinical remission. Although oncologists 
156 follow up patients with total body CT, this case report highlights the peculiarity of the follow-up of

157 adrenal masses in cancer patients. While imaging follow-up of adrenal incidentalomas is seldom

158 recommended $[4,5,31]$ any adrenal lesion in a patient with known oncological disease should be

159 carefully evaluated at any restaging, even if the mass has been previously labelled as benign. This is

160 of utmost importance when a complete response of the primary cancer has been obtained after

161 treatment, since the detection of new adrenal metastasis may change the management plan. In this

162 clinical scenario, ${ }^{18} \mathrm{~F}$-FDG-PET/CT represents a valid tool to guide clinicians in the decision-making 163 process [52].

\section{Conflict of Interest}

166 On behalf of all authors, the corresponding author states that there is no conflict of interest.

\section{REFERENCES}

1. Terzolo M, Stigliano A, Chiodini I, Loli P, Furlani L, Arnaldi G et al. (2011) AME position statement on adrenal incidentaloma Eur J Endocrinol 164:851-70.

2. Cingam SR, Karanchi H (2019) Cancer, Adrenal Metastasis. StatPearls Publishing

3. Untch BR, Shia J, Downey RJ, Carrasquillo JA, Panicek DM, Strong VE (2014) Imaging and management of a small cell lung cancer metastasis/adrenal adenoma collision tumor: a case report and review of the literature. World J Surg Oncol 12:45.

4. Fassnacht M, Arlt W, Bancos I, Dralle H, Newell-Price J, Sahdev A et al. (2016) Management of adrenal incidentalomas: European Society of Endocrinology Clinical Practice Guideline in collaboration with the European Network for the Study of Adrenal Tumors Eur J Endocrinol 175:G1-G34.

5. Elhassan YS, Alahdab F, Prete A, Delivanis DA, Khanna A, Prokop L et al. (2019) Natural History of Adrenal Incidentalomas With and Without Mild Autonomous Cortisol Excess: A Systematic Review and Meta-analysis Ann Intern Med 171:107-116. 
6. Caoili EM, Korobkin M, Francis IR, Cohan RH, Dunnick NR (2000) Delayed enhanced CT of lipid-poor adrenal adenomas AJR Am J Roentgenol 175:1411-5.

7. Peña CS, Boland GW, Hahn PF, Lee MJ, Mueller PR (2000) Characterization of indeterminate (lipid-poor) adrenal masses: use of washout characteristics at contrast-enhanced CT Radiology 217:798-802.

8. Zhang HM, Perrier ND, Grubbs EG, Sircar K, Ye ZX, Lee JE, et al. (2012) CT features and quantification of the characteristics of adrenocortical carcinomas on unenhanced and contrast-enhanced studies Clin Radiol 67:38-46.

9. Dunnick NR, Korobkin M (2002) Imaging of adrenal incidentalomas: current status AJR Am J Roentgenol 179:559-68.

10. Haider MA, Ghai S, Jhaveri K, Lockwood G (2004) Chemical shift MR imaging of hyperattenuating ( $>10$ HU) adrenal masses: does it still have a role? Radiology 231:711-6.

11. Bharwani N, Rockall AG, Sahdev A, Gueorguiev M, Drake W, Grossman AB, et al. (2011) Adrenocortical carcinoma: the range of appearances on CT and MRI AJR Am J Roentgenol 196:W706-14.

12. Zukotynski K, Lewis A, O'Regan K, Jacene H, Sakellis C, Krajewski K, et al. (2012) PET/CT and renal pathology: a blind spot for radiologists? Part 1, primary pathology AJR Am J Roentgenol 199:W163-7.

13. Alencar GA, Fragoso MC, Yamaga LY, Lerario AM, Mendonca BB (2011) (18)F-FDG-PET/CT imaging of ACTH-independent macronodular adrenocortical hyperplasia (AIMAH) demonstrating increased (18)F-FDG uptake J Clin Endocrinol Metab 96:3300-1.

14. Ansquer C, Scigliano S, Mirallié E, Taïeb D, Brunaud L, Sebag F, et al. (2010) 18F-FDG PET/CT in the characterization and surgical decision concerning adrenal masses: a prospective multicentre evaluation Eur $\mathrm{J}$ Nucl Med Mol Imaging 37:1669-78.

15. Guerin C, Pattou F, Brunaud L, Lifante JC, Mirallié E, Haissaguerre M, et al. (2017) Performance of 18F-FDG Endocrinol Metal 102:2465-72.

16. Dinnes J, Bancos I, Ferrante di Ruffano L, Chortis V, Davenport C, Bayliss S, et al (2016) Imaging for the diagnosis of malignancy in incidentally discovered adrenal masses - a systematic review and meta-analysis Eur J Endocrinol 175: R51-64.

17. Albano D, Agnello F, Midiri F, Pecoraro G, Bruno A, Alongi P et al. (2019) Imaging features of adrenal masses. Insights Imaging 10:1.

18. Twomey P, Montgomery C, Clark O (1982) Successful treatment of adrenal metastases from large-cell carcinoma of the lung JAMA 248:581-3. 
20. Higashiyama M, Doi O, Kodama K, Yokouchi H, Imaoka S, Koyama H (1994) Surgical treatment of adrenal metastasis following pulmonary resection for lung cancer: comparison of adrenalectomy with palliative therapy Int Surg 79:124-9.

21. Kim SH, Brennan MF, Russo P, Burt ME, Coit DG (1998) The role of surgery in the treatment of clinically isolated adrenal metastasis Cancer 82:389-94.

22. Porte H, Siat J, Guibert B, Lepimpec-Barthes F, Jancovici R, Bernard A, et al. (2001) Resection of adrenal metastases from non-small cell lung cancer: a multicenter study Ann Thorac Surg 71:981-5.

23. Pfannschmidt J, Schlolaut B, Muley T, Hoffmann H, Dienemann H (2005) Adrenalectomy for solitary adrenal metastases from non-small cell lung cancer Lung Cancer 49:203-7.

24. Tanvetyanon T, Robinson LA, Schell MJ, Strong VE, Kapoor R, Coit DG, et al. (2008) Outcomes of adrenalectomy for isolated synchronous versus metachronous adrenal metastases in non-small-cell lung cancer: a systematic review and pooled analysis J Clin Oncol 26:1142-7.

25. Raz DJ, Lanuti M, Gaissert HC, Wright CD, Mathisen DJ, Wain JC (2011) Outcomes of patients with isolated adrenal metastasis from non-small cell lung carcinoma Ann Thorac Surg 92:1788-93.

26. Ramsingh J, O'Dwyer P, Watson C (2019) Survival outcomes following adrenalectomy for isolated metastases to the adrenal gland Eur J Surg Oncol 45:631-4.

27. Marangos IP, Kazaryan AM, Rosseland AR, Røsok BI, Carlsen HS, Kromann-Andersen B, et al (2009) Should we use laparoscopic adrenalectomy for metastases? Scandinavian multicenter study J Surg Oncol 100:43-7.

28. Moreno P, de la Quintana Basarrate A, Musholt TJ, Paunovic I, Puccini M, Vidal O, et al. (2013) Adrenalectomy for solid tumor metastases: results of a multicenter European study Surgery 154:1215-23.

29. Puccini M, Panicucci E, Candalise V, Ceccarelli C, Neri CM, Buccianti P, et al. (2017) The role of laparoscopic resection of metastases to adrenal glands Gland Surg 6:350-4. adrenalectomy for metastatic disease: Retrospective cohort with long-term, comprehensive follow-up Surgery 165:958-64.

31. Terzolo M, Reimondo G (2019) Insights on the Natural History of Adrenal Incidentalomas Ann Intern Med 171:135-136.

32. Pakalniskis MG, Ishigami K, Pakalniskis BL, Fujita N (2019). Adrenal collision tumour comprised of adrenocortical carcinoma and myelolipoma in a patient with congenital adrenal hyperplasia. J Med Imaging Radiat Oncol.

33. Foresti M, Parmiggiani A (2019) Adrenal Adenoma-Hemangioma Collision Tumor: Description of Two Cases. J Radiol Case Rep 13:1-12.

34. Khorsand A, Khatami F, Sefidbakht S, Saffar H, Sadeghipour A, Tavangar SM (2018) Adrenal Collision Tumor Composed of Pheochromocytoma and Diffuse Large B-Cell Lymphoma: A Case Report. Int J Hematol Oncol Stem Cell Res 12:249-252. 
35. Lai Y, Zhou L, Hu J, Li W, Cui L, Lai Y, Ni L (2018) Erratum: Adrenal collision tumor (parachordoma and ganglioneuroma): A case report. Mol Clin Oncol 9:238.

36. Zhang CX, Tian Y (2018) Adrenal Collision Tumor Composed of Adrenocortical Adenoma and Pheochromocytoma. Chin Med J (Engl). 131:374-375.

37. Liu D, Kumar SA (2017) An exceedingly rare adrenal collision tumor: adrenal adenoma-metastatic breast cancer-myelolipoma. J Community Hosp Intern Med Perspect 7:241-244.

38. Takizawa K, Kohashi K, Negishi T, Taguchi K, Yamada Y, Nakamura M, et al (2017) A exceptional collision tumor of primary adrenal angiosarcoma and non-functioning adrenocortical adenoma. Pathol Res Pract 213:702-705.

39. Lee HS, Choi YJ, Kim C, Kim BH (2016) Adrenal Collision Tumor: Coexistence of Pigmented Adrenal Cortical Oncocytoma and Ganglioneuroma. Case Rep Surg 5790645.

40. Piotrowski Z, Tomaszewski JJ, Hartman AL, Edwards K, Uzzo RG (2015) Renal cell carcinoma and an incidental adrenal lesion: adrenal collision tumors. Urology 85:e17-8.

41. Hayashi T, Gucer H, Mete O (2014) A mimic of sarcomatoid adrenal cortical carcinoma: epithelioid angiosarcoma occurring in adrenal cortical adenoma. Endocr Pathol 25:404-9.

42. Wang J1, Fisher C1, Thway K2 (2014) "Dominant" myelolipoma encasing adrenal cortical carcinoma: an unusual variation of myelolipoma occurring as a synchronous and predominant neoplasm Int J Surg Pathol $22: 731-5$.

43. Abdullazade I. S., Tezel G (2012) A rare case of collision tumor: coexistence of adrenocortical adenoma and pheochromocytoma in the same adrenal gland Journal of Medical Cases 3:63-67.

44. Siddiqi AJ, Miller FH, Kasuganti D, Nikolaidis P (2009) Adrenal hemangioma-adenoma: an exceedingly rare adrenal collision tumor. J Magn Reson Imaging 29:949-52.

45. Bertolini F, Rossi G, Fiochhi F, Giacometti M, Fontana A, Gibertini MC, et al. (2011) Primary adrenal gland carcinosarcoma associated with metastatic rectal cancer: a hitherto unreported collision tumor Tumori 97:27e$30 \mathrm{e}$.

46. Thorin-Savoure A, Tissier-Rible F, Guignat L, Pellerin A, Bertagna X, Bertherat J, et al. (2005) Collision/composite tumors of the adrenal gland: A pitfall of scintigraphy imaging and hormone assays in the detection of adrenal metastasis J Clin Endo Metabol 90:4924-4929.

47. Hagspeil KD (2005) Manifestation of Hodgkin's lymphoma in an adrenal myelolipoma Eur Radiol 15:17571759.

48. Blake MA, Sweeney AT, Kalra MK, Maher MM (2004) Collision adrenal tumors on PET/CT AJR Am J Roentgenol 183:864-865.

49. Otal P, Escourrou G, Mazerolles C, Janne d'Othee B, Mezghani S, Musso S, et al. (1999) Imaging features of uncommon adrenal masses with histopathologic correlation Radiographics 19:569-581.

50. Schwartz LH, Macari M, Huvos AG, Panicek DM (1996) Collision tumors of the adrenal gland: demonstration and characterization at MR Imaging. Radiology 201:757-760.

51. Hoshi H, Jinnouchi S, Ono S, Kihara Y, Arakawa K, Takeuchi M, et al. (1984) Scintigraphic demonstration of coexisting adenoma and metastasis of the adrenal gland in a patient with bronchogenic carcinoma. Clin Nucl Med 9:717-718. 
52. Kandathil A, Wong KK, Wale DJ, Zatelli MC, Maffione AM, Gross MD, et al. (2015) Metabolic and anatomic characteristics of benign and malignant adrenal masses on positron emission tomography/computed tomography: a review of literature Endocrine 49:6-26.

290 